\title{
Effects of Two Highly Monounsaturated Oils on Lipid Composition and Enzyme Activities in Rat Jejunum
}

\author{
Carmen M. Vázquez, ${ }^{1,4}$ Rosana Zanetti ${ }^{2}$, Consuelo Santa-María, ${ }^{3}$ \\ and Valentina Ruíz-Gutiérrez ${ }^{2}$
}

Received June 19, 2000

The effects of two monounsaturated fatty acid (MUFA) oils, olive oil (OO) and high-oleic sunflower oil (HOSO), with high content in oleic acid but differing in their non-fatty acid fraction, on brush-border membrane (BBM) lipid composition and fluidity and on mucosal enzyme activities of rat jejunum were studied. Animals were given semipurified diet with linoleic acid to prevent essential fatty acid deficiency (control group) or semipurified diet containing $10 \%$ of either OO or HOSO for 12 weeks. There was a significant decrease in the content of jejunal BBM phospholipids together with an increase in the level of free cholesterol in both oil-fed rats, when compared to control group. Although the increase in the BBM free cholesterol level was not statistically significant in HOSO-fed rats, a significant decrease in the phospholipid/free cholesterol ratio was found in both OO and HOSO-fed animals compared to control group. Rat jejunal BBM had a high level of free fatty acids which was increased in BBM isolated from OO and HOSO-fed animals. There was no statistical significant difference in the phospholipid distribution between the control and the OO group. However, HOSO-fed animals showed the lowest level of phosphatidylethanolamine together with the highest phosphatidylcholine content and the phosphatidylcholine/sphingomyelin ratio. The fatty acid pattern of jejunal BBM lipids was modified according to the major fatty acids in the oils. There was a decrease in both stearic acid (18:0) and linoleic acid (18:2 n-6), together with an increase in oleic acid (18:1 $n-9)$ in jenunal BBM isolated from both oil experimental groups. All these results were accompanied by a significant increase in the BBM fluidity (as assessed by steady-state fluorescence polarization of diphenylhexatriene) isolated from oil-fed rat, when compared to control group. OO and HOSO-fed animals had the lowest activities of sucrase and maltase, while alkaline phosphatase activity only was decreased in HOSO-fed animals. The specific activity of maltase was not modified in any experimental rats. In summary, both MUFA oils induced similar effects on jejunal BBM lipid composition, fluidity, sucrase, maltase and lactase activities. Furthermore, HOSO intake resulted in a lowest alkaline phosphatase activity which was accompanied by changes in individual phospholipid composition. All these results suggest that effects of MUFA oils on jejunal BBM lipid composition and hydrolase activities are most likely due to the presence of high content of oleic acid rather than other components contained in the non-fatty acid of olive oil.

KEY WORDS: Oleic acid; olive oil; lipid composition; hydrolases; jejunum; rat.

ABBREVIATIONS: BBM, brush-border membrane; DPH, 1,6-diphenyl-1,3,5-hexatriene; FC, free cholesterol; GC, gas chromatography; GLC, gas-liquid chromatography; HOSO, high-oleic sunflower oil; HPLC, high-performance liquid chromatography; MUFA, monounsaturated fatty acid; OO, olive oil; $P$, steady-state fluorescence polarization; PC, phosphatidylcholine; PE, phosphatidylethanolamine; PL, total phospholipid; PS, phosphatidylserine $r_{s}$, steady-state fluorescence anisotropy; SM, sphingomyelin; TLC/FID, thin-layer chromatography/flame ionization detector.

\footnotetext{
${ }^{1}$ Deparamento Fisiología y Biología Animal, Facultad de Farmacia, c/o Prof. García González s/n, 41012, Sevilla, Spain. E-mail: vázquez@fafar.us.es

${ }^{2}$ Instituto de la Grasa y sus Derivados, CSIC, apdo 1078, Sevilla, Spain.

${ }^{3}$ Departamento de Bioquímica, Bromatologia y Toxicología, Facultad de Farmacia, c/Prof. García González s/n, 41012, Sevilla, Spain.

${ }^{4}$ To whom correspondence should be addressed.
} 


\section{INTRODUCTION}

It is well known that feeding diets which differ in the fatty acid composition can affect the lipid composition of cell membranes [1,2]. That in turn could influence the activity of a wide variety of membrane-bound proteins [3, 4]. Small intestine is a digestive organ and the lipid composition of its epithelial cells reflects the instantaneous apical to basolateral flux of nutrients, as well as lipid resynthesis that is going on in various compartments. On the apical surface of the intestinal enterocyte, hydrolase enzymes are responsible for the final stages of digestion.

Studies on the effect of dietary fatty acids on intestinal brush-border membrane fatty acid composition and membrane-bound enzymes have been carried out mainly with essential fatty acid deficiency [5], saturated and/or polyunsaturated fats [6-9]. However, less attention has been paid to the effect exerted by monounsaturated fatty acids (MUFA), such as oleic acid. This MUFA has received a growing interest since Mattson and Grundy [10] suggested a link between the high daily intake of olive oil and the low prevalence coronary heart disease in the mediterranean region [11]. However, the observed beneficial effect of olive oil may be due in part to other compounds contained in the non-fatty acid fraction of olive oil [12, 13].

Although olive oil (OO), an oil rich in monounsaturated fatty acids (MUFA), is the traditional source of dietary MUFA, other sources are now becoming available, such as the high-oleic sunflower oil (HOSO). Both oils have similar fatty acid composition but differ in their amount and type of plant sterols and other nonnutrients.

The objective of the present work is to study the effect of diets enriched with oleic acid, OO and HOSO, on the lipid composition and fluidity of jejunal brush border membranes and on the mucosal enzymes, sucrase, maltase, lactase and alkaline phosphatase and, to determine whether consumption of two MUFA oils with a similar fatty acid composition but differing in their non-fatty acid fraction, induces differences in the structure and function of rat jejunal brush border membranes.

\section{MATERIALS AND METHODS}

\section{Chemicals}

All chemicals were supplied by Sigma (Madrid, Spain), except for the reagents used for enzyme assays, which were from Boehringer (Mannheim, Germany) and the reagents used for the protein determination which were from Bio-Rad (Barcelona, Spain).

\section{Animals}

Male Wistar rats (Letica, Barcelona, Spain) weighing about $80 \mathrm{~g}$ at the beginning of the experiments were used. The animals were housed in a well-ventilated room maintained at $22 \pm 2^{\circ} \mathrm{C}$ on a $12 \mathrm{hr}$ light/dark cycle. The rats were randomly divided into three groups of 16 animals. Each group was fed on one of the following isocaloric and nutritionally adequate diets for 12 weeks: a semi-purified diet (Panlab SRL, Barcelona, Spain) (basal diet) containing $20 \mathrm{~g}$ lipid/Kg with sufficient linoleic 
acid, in order to avoid essential fatty acid deficiency (control group), or the basal diet containing $20 \mathrm{~g}$ lipid/ $\mathrm{Kg}$ plus $100 \mathrm{~g} / \mathrm{Kg}$ OO (OO group) or the basal diet containing $20 \mathrm{~g}$ lipid/Kg plus $100 \mathrm{~g} / \mathrm{Kg}$ HOSO (HOSO group). Feed and water were provided ad libitum. The composition of the experimental diets is shown in Table 1. All diets were identical except for their lipid component. To minimize oxidation, all diets were prepared once a week and stored at $4^{\circ} \mathrm{C}$ under an atmosphere of nitrogen until needed. Changes in composition were not detected during storage.

At the end of the feeding period, the animals were killed by decapitation. The jejunum was quickly excised, rinsed with ice-cold $0.9 \%(\mathrm{w} / \mathrm{w})$ saline solution and opened along its mesenteric border. The mucosa was scraped from the underlying layer with a glass slide and used for the experiments.

\section{Preparation of Brush-border Membrane (BBM)}

Preparation of BBM was always run in parallel on the same day from animals fed with different diets by a $\mathrm{MgCl}_{2}$ preparation method $[14,15]$ with slight modification. Mucosa scrapings were homogenized for $30 \mathrm{~s}$ in $100 \mathrm{mmol} / \mathrm{L}$ mannitol, 2 $\mathrm{mmol} / \mathrm{L}$ HEPES/Tris, $\mathrm{pH} 7.1,0.1 \mathrm{mmol} / \mathrm{L}$ benzamidine and $0.2 \mathrm{mmol} / \mathrm{L}$ phenylmethylsulfonyl fluoride, using a Waring Blender at maximal speed for $30 \mathrm{~s}$. The homogenate was filtered through nylon stocking material and $\mathrm{MgCl}_{2} 1 \mathrm{M}$ was added in order to reach a final concentration of $10 \mathrm{mmol} / \mathrm{L}$. After stirring for $20 \mathrm{~min}$, the suspension was centrifuged at $3000 \mathrm{~g}$ for $30 \mathrm{~min}$. The supernatant was centrifuged at $30,000 \mathrm{~g}$ for $30 \mathrm{~min}$. The resultant pellet was resuspended in $100 \mathrm{mM}$ mannitol, 2 $\mathrm{mM}$ Hepes/Tris, $\mathrm{pH} 7.4$, and $0.1 \mathrm{mM} \mathrm{MgSO}_{4}$. This suspension was homogenized with a glass-teflon homogenizer and centrifuged at $30,000 \mathrm{~g}$ for $30 \mathrm{~min}$. The final pellet containing purified brush-border membranes were resuspended in a medium

Table 1. Composition of Experimental Diets $(\mathrm{g} / \mathrm{Kg})$

\begin{tabular}{|c|c|c|c|}
\hline Ingredients & Control & $\mathrm{OO}$ & HOSO \\
\hline Casein & 209 & 209 & 209 \\
\hline Sucrose & 552 & 552 & 552 \\
\hline Lipids & 20 & 20 & 20 \\
\hline $\mathrm{OO}$ & - & 100 & - \\
\hline HOSO & - & - & 100 \\
\hline Cellulose powder & 152 & 52 & 52 \\
\hline Mineral mix ${ }^{a}$ & 57 & 57 & 57 \\
\hline Vitamin $\operatorname{mix}^{b}$ & 10 & 10 & 10 \\
\hline
\end{tabular}

OO, olive oil; HOSO, high-oleic acid sunflower oil.

${ }^{a}$ Mineral mix contained (mg/g): $\mathrm{NaCl} 139.3, \mathrm{~K}_{2} \mathrm{HPO}_{4}$ 389.1, $\mathrm{CaCO}_{3}$ 381.4, $\mathrm{MgSO}_{4} \cdot 7 \mathrm{H}_{2} \mathrm{O}$ 57.3, $\mathrm{FeSO}_{4} \cdot 7 \mathrm{H}_{2} \mathrm{O}$ 27.0, $\mathrm{MnSO}_{4} \cdot \mathrm{H}_{2} \mathrm{O} 4.0, \mathrm{ZnSO}_{4} \cdot 7 \mathrm{HO}_{2} 1.25, \mathrm{Kl} 0.8, \mathrm{CuCO}_{4} \cdot 5 \mathrm{H}_{2} \mathrm{O}$ $0.5, \mathrm{CoCl}_{2} \cdot 6 \mathrm{H}_{2} \mathrm{O} 0.02$.

${ }^{b}$ Vitamin mix provided (in $\mathrm{Kg}$ diet): retinol $5.9 \mathrm{mg}$; calciferols $0.15 \mathrm{mg}$; thiamin, $20 \mathrm{mg}$; riboflavin $15 \mathrm{mg}$; niacin $70 \mathrm{mg}$; pyridoxine $10 \mathrm{mg}$; inositol $150 \mathrm{mg}$; cobalamin $50 \mathrm{mg}$; tocopherols $170 \mathrm{mg}$; vitamin K $40 \mathrm{mg}$; choline $1.36 \mathrm{~g}$; pteroylmon-glutamic acid $5 \mathrm{mg}$; $p$-aminobenzoic acid $50 \mathrm{mg}$; biotin $0.3 \mathrm{mg}$. 
with $300 \mathrm{mM}$ mannitol, $0.1 \mathrm{mM} \mathrm{MgSO}_{4}$, and $20 \mathrm{mM}$ Hepes/Tris (pH 7.4) and homogenized with a 27 -gauge needle. All isolation steps were carried out at $4^{\circ} \mathrm{C}$. For each preparation of brush-border membranes, jejunum from two rats was used. All experimental groups were treated in the same manner to prevent effects which could mask differences among groups.

\section{Enzyme Assays}

The purity of brush-border membrane preparation was routinely checked by determination of the brush-border membranes marker enzyme, sucrase by the method of Dahlquist [16], and the basolateral membrane marker enzyme, $\mathrm{Na}^{+}-\mathrm{K}^{+}-$ ATPase by the method of Kinne et al. [17]. The final brush-border membrane preparation showed a 20-22-fold enrichment in sucrase specific activities and low contamination in $\mathrm{Na}^{+}-\mathrm{K}^{+}$-ATPase with respect to the original homogenate, in all experimental groups. The activities of maltase and lactase in the jejunal mucosa homogenates were measured by the method of Dahlquist [16], and the activity of alkaline phosphatase was estimated by the method of Bretaudiere et al. [18]. Protein was measured by a Coomassie Brilliant Blue protein assay using bovine gammaglobulin as standard [19].

\section{Lipid Analysis}

Total lipids were extracted from the brush-border membrane by the method of Folch et al. [20], using $0.02 \%$ (w/v) butylated hydroxytoluene (BHT) as antioxidant. The lipid extract was quantified gravimetrically and kept in a stoppered vessel under nitrogen atmosphere at $-30^{\circ} \mathrm{C}$ until the assays. Lipid and phospholipid compositions were obtained by means of the latroscan thin-layer chromatography/flame ionization detector (TLC/FID) technique [21]. Latroscan MK-5 was used in combination with Chromarods $\mathrm{S}$, which have a precoated active silica thin layer. Chromarods $\mathrm{S}$ were routinely stored in $4.5 \mathrm{~mol} / \mathrm{L} \mathrm{H}_{2} \mathrm{SO}_{4}$. Prior to use, the rods were washed with distilled water, dried at $110^{\circ} \mathrm{C}$ for $15 \mathrm{~min}$ and activated by being passed through the flame of the latroscan detector. Each rod was spotted with a $10 \mu \mathrm{L}$ Hamilton syringe containing $3 \mu \mathrm{L}$ of total lipids or phospholipids. To separate total lipids, rods were developed in hexane/diethyl ether/acetic acid (80:20:1, by vol). The phospholipids were resolved in two steps, starting with an initial development of rods in chloroform/methanol/acetic acid/water (201:84:9:6, by vol), drying at $70^{\circ} \mathrm{C}$ for $10 \mathrm{~min}$, and a second development in hexane/diethylether/acetic acid (80:20:1, by vol).

Rods were scanned under the following conditions: hydrogen flow, $150 \mathrm{~mL} /$ $\mathrm{min}$; air flow, $1750 \mathrm{~mL} / \mathrm{min}$, scanning speed, $47 \mathrm{~mm} / \mathrm{s}$; chart speed, $42 \mathrm{~mm} / \mathrm{min}$. A latrocorder TC-11 integrator was used to record and integrate the area.

\section{Fatty Acid Analysis}

Fatty acids of the total lipid extract were analyzed by gas chromatography (GC) as previously described [22]. The samples were saponified by heating for $5 \mathrm{~min}$ with $5 \mathrm{~mL}$ of $0.2 \mathrm{~mol} / \mathrm{L}$ sodium methylate and heating again at $80^{\circ} \mathrm{C}$ for $5 \mathrm{~min}$ with 
$6 \%(\mathrm{w} / \mathrm{v}) \mathrm{H}_{2} \mathrm{SO}_{4}$ in anhydrous methanol. The fatty acid methyl esters thus formed were eluted with hexane, and analyzed in a Hewlett-Packard 5890 series II gas chromatograph equipped with a flame ionization detector and using a Omegawax 320 fused silica capillary column $(30 \mathrm{~m} \times 0.32 \mathrm{~mm}$ i.d., $0.25 \mu \mathrm{m}$ film $)$. The initial column temperature was $200^{\circ} \mathrm{C}$, which was maintained for $10 \mathrm{~min}$, then programmed at $200-230^{\circ} \mathrm{C}$ and $2{ }^{\circ} \mathrm{C} / \mathrm{min}$. The injection and detector temperatures were $250^{\circ} \mathrm{C}$ and $269^{\circ} \mathrm{C}$, respectively. The flow rate of helium was $2 \mathrm{~mL} / \mathrm{min}$, the column head pressure was $250 \mathrm{kPa}$ and the detector auxiliary flow rate was $20 \mathrm{~mL} / \mathrm{min}$. Peak areas were calculated by a Hewlett-Packard 3990A recording integrator.

Individual fatty acid methyl esters were identified on isothermal runs by comparison of their retention time against those of standards. Fatty acid methyl esters were quantified by internal standardized (tricosanoic methyl ester, 23:0), using peakarea integration.

\section{Non-fatty Acid Components}

To the extraction of the unsaponified matter, $20 \mathrm{~g}$ of oils was saponified for 30 min with $75 \mathrm{~mL}$ of $10 \%$ ethanolic potassium hydroxide. The solution was passed to $5000 \mathrm{~mL}$ decanting funnel, $100 \mathrm{~mL}$ distilled water was added, and the mixture was extracted with $100 \mathrm{~mL}$ portions of hexane. The hexane solution was evaporated to dryness in a rotator evaporator at $30^{\circ} \mathrm{C}$ under reduced pressure. Sterol fraction was analysed by capillary GLC (gas-liquid chromatography) [23]. Tocopherols were analyzed by HPLC (high-performance liquid chromatography) [24]. For the assay of squalene, hydrocarbon fraction was separated from the oils by column chromatography on silica gel and analysed by capillary GLC [25]. Polyphenols fraction was determined by capillary GLC [26].

\section{Fluorescence Measurement}

The steady-state fluorescence polarization $(p)$ and fluorescence anisotropy $\left(r_{s}\right)$ were determined as previously described (27), using the lipid-soluble florescent probe 1,6-diphenyl-1,3,5-hexatriene (DPH). A stock solution of $2 \mathrm{mmol} / \mathrm{L} \mathrm{DPH}$ in tetrahydrofuran was prepared and stored in the dark at $-30^{\circ} \mathrm{C}$. Brush-border membranes equivalent to $100 \mu \mathrm{g}$ protein were incubated at $25^{\circ} \mathrm{C}$ for $1 \mathrm{~h}$ in $2 \mathrm{~mL}$ of buffered saline containing $250 \mathrm{mmol} / \mathrm{L}$ sucrose, $10 \mathrm{mmol} / \mathrm{L}$ Tris- $\mathrm{HCl}(\mathrm{pH} 7.4)$, and $2 \mu \mathrm{mol} /$ L DPH. Measurements were taken using a Perkin-Elmer 650-40 fluorescence spectrophotometer equipped with a polarizing filter. The excitation and emission wavelengths were 365 and $430 \mathrm{~nm}$, respectively.

The steady-state fluorescence polarization $(p)$ was calculated as:

$$
p=\left(I_{v v}-I_{v h} / I_{v v}+I_{v h}\right)
$$

where $I_{v v}$ and $I_{v h}$ are observed intensities measured with polarizers parallel to and perpendicular to, respectively, the vertically oriented polarizer exciting beam. The steady-state fluorescence anisotropy $\left(r_{s}\right)$ was calculated from the ratio: 


$$
r_{s}=2 p /(3-p)
$$

Corrections for light scattering were routinely made by subtracting the signal obtained from identical but unlabelled samples and contributed less than $3 \%$ to the fluorescence of the complete system.

\section{Statistical Analysis}

All results were subjected to one-way analysis of variance (ANOVA), and represent mean \pm SEM of ten animals per group. Differences in mean values between groups were assessed by the two-tailed Student's $t$-test and were considered statistically different at $p<0.05$.

\section{RESULTS}

\section{Diets}

The fatty acid composition and non-fatty acid components of the oils were analyzed and presented in Table 2 and 3, respectively. Control diet contained 16.3\% saturates (palmitic and stearic acids), 38\% monounsaturates (oleic acid) and 41.7\% and $4.1 \%$ of linoleic acid $(18: 2, n-6)$ and $\alpha$-linolenic acid $(18: 3, n-3)$, respectively, to prevent a lack of essential fatty acids. Olive oil (OO) contained $15.67 \%$ saturates (palmitic and stearic acids), 80.28\% monounsaturates (mainly oleic acid) and 4.05\% polyunsaturates, whereas the HOSO consisted of $9.96 \%$ saturates (palmitic and stearic acids), $80.54 \%$ monounsaturates (high content of oleic acid) and $9.5 \%$ polyunsaturates (Table 2).

Significant differences were noted in the amount of plant sterols, squalene, and tocopherols between the experimental oils. Total sterol concentrations were 1696 and $1754 \mathrm{mg} / \mathrm{kg}$ in the OO and HOSO, respectively (Table 3). Sitosterol was the most abundant sterol present in these oils ( $94 \%$ for OO and $59 \%$ for HOSO). However, campesterol and stigmasterol were present in less percentage in OO. The

Table 2. Fatty Acid Composition of Dietary Fats (g/100 g Total Fatty Acids)

\begin{tabular}{lccc}
\hline Fatty acids & Control & OO & HOSO \\
\hline $14: 0$ & - & - & - \\
$16: 0$ & 13.2 & 11.8 & 4.3 \\
$16: 1(n-7)$ & 1.2 & 0.9 & 0.1 \\
$17: 0$ & - & 0.4 & 0.1 \\
$18: 0$ & 3.1 & 2.8 & 4.7 \\
$18: 1(n-9)$ & 36.8 & 79.2 & 80.2 \\
$18: 2(n-6)$ & 41.7 & 3.5 & 9.4 \\
$18: 3(n-3)$ & 4.1 & 0.6 & 0.1 \\
$18: 4(n-3)$ & - & - & - \\
$20: 0$ & - & 0.3 & 0.4 \\
$20: 1(n-9)$ & - & 0.2 & 0.2 \\
$24: 0$ & & 0.4 & 0.4 \\
\hline
\end{tabular}

OO, olive oil; HOSO, high-oleic acid sunflower oil. 
Table 3. Composition in Non-fatty Acid Components of the Experimental Oils

\begin{tabular}{lcc}
\hline & OO & HOSO \\
\hline Total unsaponifiable fraction $(\mathrm{g} / \mathrm{Kg})$ & 15 & 10 \\
Total sterols $(\mathrm{mg} / \mathrm{Kg})$ & 1696 & 1754 \\
Cholesterol (\%) & 0.15 & 0.01 \\
Brasicasterol (\%) & - & 0.32 \\
Campesterol (\%) & 3.80 & 10.25 \\
Stigmasterol (\%) & 0.81 & 11.59 \\
$\beta$-Sitosterol (\%) & 93.99 & 59.35 \\
$\Delta$-5-Avenasterol (\%) & - & 2.88 \\
$\Delta$-7-Stigmasterol (\%) & 0.22 & 11.84 \\
$\Delta$-7-Avenasterol (\%) & 0.15 & 3.27 \\
Squalene (mg/Kg) & 3000 & 90 \\
Tocopherols (mg/Kg): & 47 & 10 \\
$\alpha$-tocopherols & 34 & 10 \\
$\gamma$-tocopherols & 13 & - \\
Fraction of polyphenols (mg/Kg) & 470 & - \\
Total polyphenols (mg/Kg) & 430 & - \\
Ortodiphenol (mg/Kg) & 40 & - \\
\hline
\end{tabular}

OO, olive oil; HOSO, high-oleic acid sunflower oil.

Table 4. Effect of Olive Oil (OO) and High-Oleic Sunflower Oil (HOSO) on Food Intake, Body Weight and Jejunal Mucosa Weight

\begin{tabular}{|c|c|c|c|}
\hline & Control & $\mathrm{OO}$ & HOSO \\
\hline Food intake (g/day) & $20.8 \pm 1.1$ & $21.0 \pm 0.9$ & $22.8 \pm 1.9$ \\
\hline Body wt (g) at entry & $85.1 \pm 2.3$ & $77.6 \pm 3.2$ & $78.3 \pm 3.1$ \\
\hline at study & $312.9 \pm 7.2$ & $325.9 \pm 6.1$ & $331.1 \pm 12.3$ \\
\hline Jejunal mucosa wt (g) & $2.9 \pm 0.5$ & $2.9 \pm 0.2$ & $2.8 \pm 0.2$ \\
\hline
\end{tabular}

The values represent the mean (SEM of 16 aminals per group.

amount of tocopherols was greater $(47 \mathrm{mg} / \mathrm{kg})$ in OO than in HOSO $(10 \mathrm{mg} / \mathrm{kg})$. The squalene content was 33.3 times higher in OO $(3000 \mathrm{mg} / \mathrm{kg})$ than in HOSO $(90 \mathrm{mg} / \mathrm{kg})$.

\section{Effects of Experimental Diets on Food Consumption, Body Weight and Jejunal Mucosa Weight}

Rats fed the three diets did not differ in their patterns of food consumption throughout the 12-week feeding period, during which approximately $20-23 \mathrm{~g} /$ day was consumed. All groups gained weight, and the mean body mass increased by $228-250 \mathrm{~g}$ in the three experimental groups (Table 4). Similarly, changing diets had no effect on the mucosal weights of the jejunum in any experimental groups (Table 4). 
Table 5. Effects of Olive Oil (OO) and High-Oleic Sunflower Oil (HOSO) on Percentage of Jejunal BBM Lipid Composition in Rats

\begin{tabular}{lrcc}
\hline Lipids $(\% \mathrm{w} / \mathrm{w})$ & \multicolumn{1}{c}{ Control } & \multicolumn{1}{c}{ OO } & HOSO \\
\hline Total phospholipid (PL) & $69.8 \pm 3.3^{*}$ & $42.5 \pm 1.7^{* *}$ & $34.0 \pm 2.9^{* *}$ \\
Free cholesterol (FC) & $9.9 \pm 0.8^{*}$ & $15.3 \pm 0.4^{* *}$ & $11.6 \pm 0.9^{*}$ \\
Free fatty acids & $23.6 \pm 2.8^{*}$ & $42.1 \pm 1.8^{* *}$ & $55.8 \pm 2.7^{* * *}$ \\
PL/CL & $6.0 \pm 0.6^{*}$ & $2.8 \pm 0.1^{* *}$ & $3.3 \pm 0.6^{* *}$ \\
\hline
\end{tabular}

Values represent means \pm SEM of eight separate membrane preparations, each including jejunum from two rats.

Values in each row with no common superscript differ significantly $(p<0.05)$.

FC: Free cholesterol; PL: total phospholipid.

\section{Effects of Experimental Diets on Jejunal Brush-border Membrane (BBM) Lipid Composition}

Jejunal brush-border membrane (BBM) lipid composition is shown in Table 5. There was a significant decrease in the content of phospholipid together with an increase in the level of free cholesterol in both oleic acid-rich-fed animals, when compared to control group. Although the increase in the BBM free cholesterol level was not statistically significant in HOSO-fed, a significant decrease in the phospholipid to free cholesterol ratio was found in both oil-fed animals when compared to control group. Jejunal BBM isolated from OO and HOSO-fed rats had the highest level in BBM free fatty acids.

The phospholipid composition is showed in Table 6. There were no statistical significant differences in the phospholipid distribution between the control and the OO-fed groups. However, HOSO-fed animals showed a decrease in the phosphatidylethanolamine level and an increase in both phosphatidylcholine and phosphatidylcholine/sphingomyelin ratio, when compared to the other experimental rats.

The fatty acid composition determined in jejunal BBM of different groups of animals is given in Table 7. The BBM of animals fed oil diets contained a significantly higher proportion of oleic acid and a significantly lower proportion of stearic and linoleic acid than the membranes from control groups. These results were accompanied by a significant decrease in the saturated/unsaturated ratio in BBM from oil-fed animals.

As shown in Table 8, feeding oleic acid-rich diets increased the membrane fluidity (decreased the steady-state fluorescence polarization for DPH), when compared to control group.

\section{Effects of Experimental Diets on Hydrolase Specific Activities}

Specific activities of sucrase, maltase, lactase and alkaline phosphatase in jejunal mucosa isolated from experimental groups are given in Fig. 1. A significant decrease in the activities of sucrase and maltase was found in both oil-fed rats, when compared to control rats. No significant variations were obtained for lactase activity among the three experimental groups. Feeding the HOSO diet depressed the specific 
Table 6. Effects of Olive Oil (OO) and High-Oleic Sunflower Oil (HOSO) on Percentage of Jejunal BBM Phospholipid Composition in Rats

\begin{tabular}{lccc}
\hline $\begin{array}{c}\text { Phospholipids } \\
(\% \mathrm{w} / \mathrm{w})\end{array}$ & Control & OO & HOSO \\
\hline PC & $55.6 \pm 4.0^{*}$ & $53.4 \pm 2.0^{*}$ & $70.1 \pm 3.0^{* *}$ \\
PE & $54.0 \pm 5.3^{*}$ & $53.3 \pm 3.4^{*}$ & $22.7 \pm 1.6^{* *}$ \\
PS & $12.0 \pm 1.4^{*}$ & $14.6 \pm 0.5^{*}$ & $11.8 \pm 0.2^{*}$ \\
SM & $4.5 \pm 0.5^{*}$ & $5.4 \pm 0.7^{*}$ & $3.3 \pm 0.4^{*}$ \\
PC/SM & $13.0 \pm 1.1^{*}$ & $9.6 \pm 1.7^{*}$ & $22.5 \pm 1.8^{* *}$ \\
\hline
\end{tabular}

The values represent the mean \pm SEM of eight separate membrane preparations, each including jejunum from two rats.

Values in each row with no common superscript differ significantly $(p<0.05)$.

$\mathrm{PC}=$ phosphatidylcholine.

$\mathrm{PS}=$ phosphatidylserine.

$\mathrm{PE}=$ phosphatidylethanolamine.

$\mathrm{SM}=$ sphingomyelin.

Table 7. Effects of Olive Oil (OO) and High-Oleic Sunflower Oil (HOSO) on Jejunal BBM Fatty Acid Composition in Rats

\begin{tabular}{lccc}
\hline Fatty acids $(\% \mathrm{w} / \mathrm{w})$ & Control & OO & HOSO \\
\hline $14: 0$ & $1.2 \pm 0.3^{*}$ & $1.9 \pm 0.2^{*}$ & $1.6 \pm 0.3^{*}$ \\
$16: 0$ & $22.2 \pm 1.6^{*}$ & $23.1 \pm 1.2^{*}$ & $21.2 \pm 0.7^{*}$ \\
$16: 1(n-9)$ & $1.5 \pm 0.3^{*}$ & $1.8 \pm 0.1^{*}$ & $1.9 \pm 0.4^{*}$ \\
$18: 0$ & $21.4 \pm 0.3^{*}$ & $13.9 \pm 0.4^{* *}$ & $12.5 \pm 0.5^{* *}$ \\
$18: 1(n-9)$ & $12.6 \pm 1.9^{*}$ & $33.7 \pm 2.4^{* *}$ & $34.2 \pm 0.9^{* *}$ \\
$18: 2(n-6)$ & $16.9 \pm 1.0^{*}$ & $9.6 \pm 0.4^{* *}$ & $11.4 \pm 0.5^{* *}$ \\
$20: 4(n-6)$ & $7.6 \pm 0.6^{*}$ & $9.9 \pm 0.7^{*}$ & $8.5 \pm 0.5^{*}$ \\
$22: 4(n-6)$ & $0.6 \pm 0.01^{*}$ & $0.6 \pm 0.04^{*}$ & $0.5 \pm 0.02^{*}$ \\
$22: 6(n-3)$ & $0.7 \pm 0.10^{*}$ & $0.9 \pm 0.09^{*}$ & $0.7 \pm 0.08^{*}$ \\
Saturated & $44.8 \pm 1.7^{*}$ & $38.9 \pm 0.3^{* *}$ & $35.3 \pm 0.7^{* *}$ \\
Monounsaturated & $14.7 \pm 0.5^{*}$ & $35.5 \pm 1.7^{*} 8$ & $36.1 \pm 0.6^{* *}$ \\
Polyunsaturated & $25.8 \pm 1.7^{*}$ & $21.0 \pm 0.4^{* *}$ & $21.1 \pm 0.6^{* *}$ \\
Saturated/unsaturated & $1.1 \pm 0.01^{*}$ & $0.68 \pm 0.02^{* *}$ & $0.62 \pm 0.02^{* *}$ \\
\hline
\end{tabular}

The values represent the mean \pm SEM of eight separate membrane preparations, each including jejunum from two rats.

Values in each row with no common superscript differ significantly $(p<0.05)$.

Table 8. Effects of Olive Oil (OO) and High-Oleic Sunflower Oil (HOSO) on Steady-State Fluorescence Polarization $\left(\mathrm{P}_{\mathrm{DPH}}\right)$ and Steady-State Fluorescence Anisotropy $\left(r_{s}\right)$ Percentage of Jejunal BBM in Rats

\begin{tabular}{lccc}
\hline Parameter & Control & OO & HOSO \\
\hline $\mathrm{P}_{\mathrm{DPH}}$ & $0.374 \pm 0.003^{*}$ & $0.346 \pm 0.002^{* *}$ & $0.349 \pm 0.002^{* *}$ \\
$r_{s}$ & $0.285 \pm 0.002^{*}$ & $0.261 \pm 0.002^{* *}$ & $0.263 \pm 0.002^{* *}$ \\
\hline
\end{tabular}

The values represent the mean \pm SEM of eight separate membrane preparations, each including jejunum from two rats.

Values in each row with no common superscript differ significantly $(p<0.05)$. 

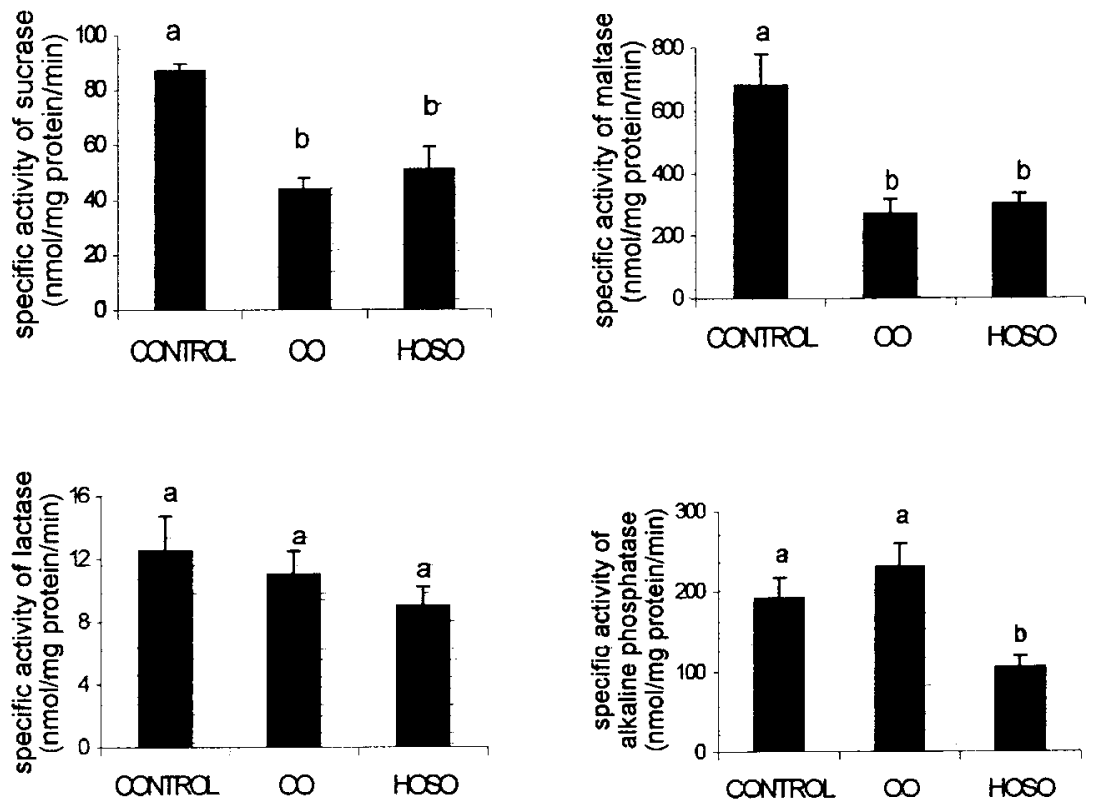

Fig. 1. Effects of olive oil (OO) and high-oleic acid sunflower oil (HOSO) on sucrase, maltase, lactase and alkaline phosphatase specific activities in rat jejunal mucosa. Values represent mean \pm SEM of 16 animals per group. Values in each panel with no common superscript differ significantly $(p<0.05)$.

activity of alkaline phosphatase in comparison with those observed in control and OO-feed rats.

\section{DISCUSSION}

Effects of two oils, OO and HOSO, both with the same high content of MUFAs (oleic acid) (80.28\% for OO versus $80.54 \%$ for HOSO) on BBM lipid composition and fluidity and, on mucosal specific activities of sucrase, maltase, lactase and alkaline phosphatase of rat jejunum were studied. The results demonstrate that both oleic acid-rich oils cause similar effects on jejunal BBM lipid composition. An increase in the level of free cholesterol, although not significant for HOSO, together with a decrease in the content of phospholipid were observed in OO and HOSO-fed rats, when compared with control group. As a consequence, a decrease in the phospholipid/cholesterol ratio was found in animals fed with both oils. Similar results were found in serum and liver from rats fed with OO or HOSO diets [28, 29]. The observed increase in jejunal BBM cholesterol level together with the decrease in the phospholipid content might be related to changes in the synthesis of both cholesterol and phospholipids in the jejunum of rats fed with OO or HOSO diets. Thus, Cha and Jones [30] found that olive oil feeding was associated with higher cholesterol synthesis rate in the rat small intestine compared with other fats, and Gupta et al. [31], studying intestinal BBM lipid composition in mice suggested that, the observed 
decrease in phospholipid content in animals feeding high-fat diet was due to reduced synthesis of this constituents.

The level of free fatty acids were high in the jejunal BBM of three experimental rats. Similar high content of free fatty acids has been previously observed in intestinal BBM from monkey [32]. Furthermore, feeding OO or HOSO diets increased the content of BBM free fatty acids. These results suggest that oleic acid-rich diets might induce changes in enzyme involved in intestinal fatty acids metabolism, such as phospholipases, and protect these membranes from lipid peroxidation as previously reported [33].

Although no changes in the jejunal BBM total phospholipids were observed between both oleic acid-rich diets, phospholipid composition was different between $\mathrm{OO}$ and HOSO-fed rats, and it was modified in HOSO-fed animals, when compared to control and OO-fed groups. A decrease in the level of phosphatidylethanolamine together with an increase in the content of phosphatidylcholine and in the phosphatidylcholine/sphingomyelin ration were found in jejunal BBM from HOSO-fed rats when compared to the other groups. These results are not in agreement with previous work in our lab [34], that showed no significant differences in biliary phospholipid distribution between $\mathrm{OO}$ and HOSO-fed rats. However, dietary polyunsaturated fatty acid deficiency induced variations in piglet intestinal BBM phospholipid classes [8].

OO and HOSO diets had similar effects on the jejunal BBM fatty acid composition. As expected, an increase in the level of oleic acid was observed in both OO and HOSO-fed rats, that induced to an increase in the content of MUFA in these rat membranes, when compared to the control group. The content of linoleic acid was decreased while the level of arachidonic acid was not modified by the addition of oleic acid-rich fat to the diets. Since the content of arachidonic acid, which is a product from desaturation of linoleic acid, is not modified in oleic acid-rich-fed animals, these data suggest that there may have been an increase of $\Delta^{6}$-desaturase activity in the jejunum of rats fed with OO and HOSO to maintain arachidonic acid levels. In addition, a reduced saturated (mainly stearic acid)/unsaturated ratio was observed in oil-fed animals. Similar results were previously found in liver fatty acid composition of rats fed OO or HOSO [29, 35] and in erythrocyte membranes of dogs fed with olive oil [2].

Differences in membrane fluidity may be secondary to alterations in the phospholipid/cholesterol, phosphatiidylcholine/sphingomyelin and saturated/unsaturated ratios [36]. Our data indicated a decrease in phospholipid/cholesterol ratio in $\mathrm{OO}$ and HOSO-fed rats, that was not well correlated with data of the steady-state fluorescence polarization which showed an increase in the BBM fluidity from these animals, when compared to the control group. However, the saturated/unsaturated ratio was decreased in oil-fed animals and in HOSO-fed rats, an increase in phosphatiidylcholine/sphingomyelin ratio was found, both results being associated with the increase in the BBM fluidity from oil-fed animals.

It is well known that dietary fats, such as saturated and/or unsaturated ones, affect intestinal membrane lipid composition and enzyme activities [5-9]. However, little attention has been paid to oleic acid-rich fats. The brush-border membrane hydrolases are membrane-bound glycoproteins located on the apical surface of the 
intestinal enterocyte and, are responsible for the final stages of digestion. As previously shown $[7,9,38]$, feeding diets with different oils modify the activities of membrane hydrolases by changing in the brush-border membrane lipid composition and fluidity. Our results show that sucrase, and maltase specific activities were diminished in $\mathrm{OO}$ and HOSO-fed animals when compared to control group. However, lactase activity was not modified in any groups and alkaline phosphatase was only significantly decreased in HOSO-fed rats. According to previous reports [9], the activities of sucrase was lower in animals fed the unsaturated high fat diet than in animals fed saturated high fat diets. In addition, a high unsaturated fat/low carbohydrate diet was associated with low activities of sucrase [37]. These oleic acid-rich diets could have affected hydrolyase activities via changes in the state and/or lipid composition of BBM and/or via direct effect on these enzymes. Since OO and HOSO-fed rats had the same behaviour on fluidity, lipid composition and sucrase, maltase and lactase specific activities of jejunal mucosa, these results suggest that these effects are most likely due to oleic acid rather than other components contained in the nonfatty acid fraction of olive oil. However, feeding HOSO diets showed a decrease in the specific activity of alkaline phosphatase, which was accompanied by an increase in the percentage of PC and a decrease in the level of PE in the apical membranes from HOSO-fed rats.

It has been reported that the specific activity of alkaline phosphatase is increased by saturated fatty acids [38]. Since HOSO diet contained a lesser amount of saturated fatty acids when compared to control and OO diet, it is possible that this HOSO diet induced a decrease in the activity of alkaline phosphatase. In addition, the stereospecific distribution of fatty acids on triacylglycerol structures might play an important role in both the specific activities of hydrolases and the lipid composition of jejunal mucosa, as previously described $[39,40]$. Since differences in this specific distribution was previously observed between OO and HOSO diets [34], it is possible that these changes might explain the effect of HOSO diets on alkaline phosphatase specific activity and on phospholipid distribution in the apical membranes from these animals.

In conclusion, these results show a clear effect of oleic acid-rich diets on fluidity, lipid composition and hydrolase activities of rat jejunum, and suggest that other components contained in the non-fatty acid fraction of olive oil are not responsible for these changes.

\section{ACKNOWLEDGEMENTS}

This study was supported by a Grant ALI96-0456 from the Comisión Interministerial de Ciencia y Tecnologia, Spain. We wish to thank Koipe S.A. and Aceites Toledo, Industria, for kindly providing the oils used in this study. R. Zanetti was supported by a grant from Instituto de Cooperación Iberoamericana (ICI).

\section{REFERENCES}

1. Barzanti, V., Battino, M., Baracca, A., Cavazzoni, M., Cocchi, M., Noble, R., Maranesi, M., Turchetto, E., and Lenaz, G. (1994) The effect of dietary lipid changes on the fatty acid composition and function of liver, heart and brain mitochondria in the rat at different ages. J. Nutr. 71:193-202. 
2. Giron, M. D., Mataix, F. J., and Suarez, M. D. (1992) Long-term effects of dietary monounsaturated and polyunsaturated fatty acids on the lipid composition of erythrocyte membranes in dogs. Comp. Biochem. Physiol. 102:197-201.

3. Muriana, F. J. G., Ruiz-Gutierrez, V., and Vázquez, C. M. (1992) Influence of dietary cholesterol on polyunsaturated fatty acid composition, fluidity and membrane-bound enzymes in liver microsomes of rats fed olive and fish oil. Biochimie 74:551-556.

4. Bartoli, G. M., Palozza, P., Luberto, C., Franceschelli, P., and Piccioni, E. (1995) Dietary fish oil inhibits human erythrocyte $\mathrm{Mg}-\mathrm{Na}-\mathrm{K}-\mathrm{ATPase}$. Biochem. Biophys. Res. Commun. 213:881-887.

5. Christon, R., Meslin, J. C., Thévenoux, J., Linard, A., Léger, C. L., and Delpal, S. (1991) Effects of a low dietary linoleic acid level on intestinal morphology and enterocyte brush border membrane lipid composition. Reprod. Nutr. Dev. 31:691-701.

6. Wang, H., Dudley, A. W. Jr, Dupont, J., Reeds, P. J., Hachey, D. L., and Dudley, M. A. (1996) The duration of medium-chain triglyceride feeding determines brush border membrane lipid composition and hydrolase activity in newly weaned rats. J. Nutr. 126:1455-1462.

7. Kaur, M., Kaur, J., Ojha, S., and Mahmood, A. (1996) Dietary fat effects on brush border membrane composition and enzyme activities in rat intestine. Ann. Nutr. Metab. 40:269-276.

8. Daveloose, D., Linard, A., Arfi, T., Viret, J., and Christor, R. (1993) Simultaneous changes in lipid composition, fluidity and enzyme activity in piglet intestinal brush border membrane as affected by dietary polyunsaturated fatty acid deficiency. Biochim. Biophys. Acta, 1166:229-237.

9. Dudley, M. A., Wang, H., Hachey, D. L., Shulman, R. J., Perkinson, J. S., Rosenberger, J., and Mersmann, H. J. (1994) Jejunal brush border hydrolase activity is higher in tallow-fed pigs than in corn oil-fed pigs. J. Nutr. 124:1996-2005.

10. Mattson, F. H. and Grundy, S. M. (1985) Comparison of effects of dietary saturated, monounsaturated and polyunsaturated fatty acids on plasma lipids and lipoproteins in man. J. Lipid. Res. 26:194202.

11. Dougherty, R. M., Galli, C., Ferro-Luzzi, A., and Iacono, J. M. (1987) Lipid and phospholipid fatty acid composition of plasma, red blood cells and platelets and how they are affected by dietary lipids: a study of normal subjects from Italy, Finland and the USA. Am. J. Clin. Nutr. 45:443-455.

12. Becker, M., Staab, D., and Von Bergmann, K. (1993) Treatment of severe familial hypercholesterolemia in childhood with sitosterol and sitostanol, J. Pediatr. 122:292-296.

13. Becker, M., Staab, D., and Von Bergmann, K. (1992) Long term treatment of severe familial hypercholesterolemia in children: effect of sitosterol and bezafibrate. Pediatrics 89:138-142.

14. Vázquez, C. M., Rovira, N., Ruiz-Gutierrez, V., and Planas, J. M. (1997) Developmental changes in glucose transport, lipid composition, and fluidity of jejunal BBM. Am. J. Physiol. 273:R1086-R1093.

15. Vázquez, C. M., Zanetti, R., and Ruiz-Gutiérrez, V. (1996) Lipid composition and fludity in the jejunal brush-border membrane of spontaneously hypertensive rats. Effects on activities of membrane-bound proteins. Biosci. Rep. 16:217-226.

16. Dahlquist, A. (1964) Method for assay of intestinal disaccharides, Analytical Biochem. 7:18-25.

17. Kinne, R., Schmitz, J. E., and Kinne-Saffran, E. (1971) The localization of the $\mathrm{Na}^{+}-\mathrm{K}^{+}$-ATPase in the cells of rat kidney cortex. A study on isolated plasma membranes. Pflügers Arch. 329:191-209.

18. Bretaudiere, J. P., Vassault, A., Amsellem, L., Pourc, M. L., Thieu-Phung, H., and Bailly, M. (1977) Criteria for establishing a standardized method for determining alkaline phosphatase actdivity in human serum. Clin. Chem. 23:2263-2274.

19. Bradford, M. M. (1976) A rapid and sensitive method for the quantitation of microgram quantities of protein utilising the principle of protein-dye binding. Analytical Biochem. 72:248-254.

20. Folch, J., Less, M., and Sloan-Stanley, G. H. (1957) A sample method for the isolation and purification of total lipids from the animal tissues. J. Biol. Chem. 33:497-509.

21. De Schrijver, R., and Vermeulen, D. (1991) Separation and quantification of phospholipids in animal tissues by latroscan TLC/FID, Lipids 26:74-76.

22. Molina, M. T., Vázquez, C. M., and Ruiz-Gutiérrez, V. (1989) Changes in both acyl-CoA:cholesterol acyltransferase activity and microsomal lipid composition in rat liver induced by distal small-bowel resection. Biochem. J. 260: 115-119.

23. Garcia Regueiro, J. A., Gibert, J., and Diaz, I. (1994) Determination of neutral lipids from subcutaneous fat of cured ham by capillary gas chromatography and liquid chromatography. J. Chromatogr. 667:225-233. 
24. Kramer, J. K., Blais, L., Fouchard, R. C., Melnyk, R. A., and Kallery, K. M. (1997) A rapid method for the determination of vitamin $\mathrm{E}$ forms in tissues and diet by high-performance liquid chromatography using a normal-phase diol column. Lipids 32:323-330.

25. Sulpice, J. C. and Ferezou, J. (1984) Squalene isolation by HPLC and quantitative comparison by HPLC and GLC. Lipids 19:631-635.

26. Arce, L., Rios, A., and Valcarcel, M. (1998) Determination of anti-carcinogenic polyphenols present in green tea using capillary electrophoresis coupled to a flow injection system. J. Chromatogr. 827:113-120.

27. Vorbeck, M. L., Martin, A. P., Long, J. W., Smith, J. M., and Orr, R. R. (1982) Aging dependent modification of the lipid composition and lipid structure order parameter of hepatic mitochondria. Arch. Biochem. Biophys. 217:351-361.

28. Jeffery, N. M., Yaqoob, P., Newsholme, E. A., and Calder, P. C. (1996) The effects of olive oil upon rat serum lipid levels and lymphocyte functions appear to be due to oleic acid. Ann. Mutr. Metab. 40: $71-80$

29. Perona, J. S. and Ruiz-Gutiérrez, V. (1998) Two highly monounsaturated oils, olive oil and higholeic sunflower oil, induce different triacylglycerol molecular species distribution in rat liver. Nutr. Research. 18:1723-1732.

30. Cha, M. C. and Jones, P. J. (1997) Dietary fat type related changes in tissue cholesterol and fatty acid synthesis are influenced by energy intake level in rats, J. Am. Coll. Nutr. 16:592-599.

31. Gupta, R., Jaswal, V. M., and Mahmood, A. (1993) Effect of high-fat diet on mice intestinal brush border membrane composition. Indian J. Exp. Biol. 31:536-539.

32. Ibrahim, S. A. and Balasubramanian, K. A. (1995) Lipid composition and membrane fluidity of monkey small intestinal brush border membrane: regional differences, Biochim. Biophys. Acta 32:290-294.

33. Ibrahim, S. A. and Balasubramanian, K. A. (1993) Modulation of monkey small intestinal brush border membrane D-glucose transport by nonesterified fatty acids, Indian J. Biochem. Biophys. 30: $172-176$.

34. Vázquez, C. M., López, M. R., Bravo, L., and Ruiz-Gutiérrez, V., Comparison of effects of two different monounsaturated oils on biliary secretion in rats. Nutr. Res., in press.

35. Ruiz-Gutiérrez, V., Pérez-Espinosa, A., Vázquez, C. M., and Santa-María, C. Effects of dietary fats (fish, olive and high-oleic sunflower oils) on lipid composition and antioxidant enzymes in rat liver. British. J. Nutr., in press.

36. Van Blitterswijk, W. J., Van Der Meer, B. W., and Hilkmann, H. (1987) Quantitative contributions of cholesterol and the individual classes of phospholipids and their degree of fatty acyl (un)saturation to membrane fluidity measured by fluorescence polarization, Biochemistry 26:1746-1756.

37. McCrathy, D. M., Nicholson, J. A., and Kim, Y. S. (1980) Intestinal enzyme adaptation to normal diets of different composition. Am. J. Physiol. 239:G445-G451.

38. Bernard, A., Caselli, C., Blond, J. P., and Carlier, H. (1992) Diet fatty acid composition, age and rat jejunal microvillus enzyme activities. Comp. Biochem. Physiol. 101:607-612.

39. Takase, S. and Goda, T. (1990) Effects of medium-chain triglycerides on brush border membranebound enzyme activity in rat small intestine, J. Nutr. 120:969-976.

40. Brasitus, T. A., Davidson, N. O., and Schachter, D. (1985) Modifications in dietary triacylglycerol saturation alter the lipid composition and fluidity of rat intestinal plasma membranes, Biochim. Biophys. Acta 812:460-472. 